Index Copernicus Value: 5.88 ISSN (e)-2347-176x ISSN (p) 2455-0450 crossref DOI:_http://dx.doi.org/10.18535/jmscr/v4i6.80

\title{
A Survey on Clinicians Choices of Restorative Materials for Pediatric Patients
}

\author{
Authors \\ Sanjay Madhavan ${ }^{1}$, Dr GeoMani \\ ${ }^{1}$ III year BDS, Saveetha Dental College, Chennai \\ ${ }^{2}$ Department of Pedodontics and Preventive Dentistry, Saveetha Dental College, Chennai
}

\begin{abstract}
Aim: The aim of the study is to examine selection of various restorative materials in children; and the basis for the selection among dentists.

Background: There has been an expansion in the range of tooth-coloured materials available for restoring primary and young mixed dentitions. In addition to amalgam and stainless steel crowns, improved conventional glass ionomer cements and composite resins, resin-modified glass ionomer cements and polyacrylic acid modified composites (compomers) have become available. Many changes have occurred in the development and availability of dental restorative materials for pediatric patients and hence no consistent guidelines have been developed for material selection, and choice appears based upon clinician preference.
\end{abstract}

Materials and methods: A survey was conducted among 170 dental practionners of Saveetha Dental College, Chennai. A self administered questionnaire was distributed and descriptive data in terms of percentage was analysed.

Result: The age group of the respondents ranged from 20-27 years. GIC was the choice of material for primary anterior(78\%) and posterior(56\%) dentition in children mainly because of its fluoride releasing property(67\%). GIC was the material of choice for deep caries without pulp exposure(76\%) and for restoration of proximal caries $(81 \%)$. Dycal(44\%) was the material of choice for sterile mechanical exposure of the pulp. $82 \%$ chose pit and fissure sealant as material of choice for non-cavitated incipient carious lesion.

Conclusion: It has been observed that at times dentists find it difficult to decide on the technique and materials to use for restoration of deciduous and permanent teeth in children. The aim of this study was to examine the current choices and utilization of materials by clinicians in pediatric patients and the material of choice was found to be GIC.

Keywords: practitioners, pediatrics, deciduous, permanent, GIC, amalgam, composite. 


\section{INTRODUCTION}

In the last decade there has been a significant growth in the range of tooth-colored materials available to restore primary and mixed dentition in children. An improved conventional glass ionomer cements, composite resins, ${ }^{[1,2]}$ resinmodified glass ionomer cements, ${ }^{[3]}$ light cured glass ionomer cements, silver reinforced glass ionomer cements and polyacrylic acid modified composites (compomers) have become available in addition to amalgam and stainless steel crowns. The daily practice of pediatric dentistry at the time of the formation of the American Academy of Pediatric Dentistry didn't enjoy the numerous choices available in today's practice. For posterior teeth, the practitioner was limited to amalgam, stainless-steel crowns, or possibly steel orthodontic bands retained with a luting cement, which were also used as a restoration. The anterior teeth were restored with silicate cement, acrylic, or other esthetically less-than desirable restorations. Today, the pediatric dental practitioner is confronted with many materials from which to select for each restorative situation. The number of choices, while allowing more control of the final result, also creates confusion in terms of how to distinguish the uses of these various materials ${ }^{[4]}$.

Restoration of carious primary teeth is extremely important and significant not only for the healthy development and psychic state of the child but also for normal development of permanent teeth [5]. The choice of restorative materials for primary teeth has a lot of varieties at the present time. The purpose of this study was to find the preferred restorative material of dentists for routine restorations in primary teeth in children.

\section{MATERIALS AND METHOD}

In this study a random of 170 dental practitioners of Saveetha Dental College was chosen, which included the undergraduates and post graduates who have been treating pediatric patients in their routine practice. A 15 -item questionnaire with the choice to choose multiple options was created for this study to assess the choice of materials used by dentists in primary teeth in children. The questionnaire included queries covering the demographic details(age, gender, practice type, years of practice), number of children seen in a week, ideal requirements, factors affecting their choice of restorative material, choice of restorative material in various clinical scenarios, the influential factors in choosing a restorative material and factors that influence the success of a restoration.

Questionnaires were distributed to the dental practitioners and filled questionnaires were collected. Data was entered in Microsoft Excel spreadsheet and descriptive data in terms of percentage was analysed.

\section{RESULTS}

170 dental practitioners completed the questionnaire. The respondents age ranged from 20 to 27 . Among the 170 study subjects, were 140 Under-graduates and 30 Post-graduates.

Figure 1 depicts the distribution of study subjects based on number of years in clinical practice.

\section{FIGURE 1:}

\section{years of practice}

$\square 1-2$ yrs $\square 2-3$ yrs $\square 3-4$ yrs $\square$ 4-5 yrs $\square 5-6$ yrs

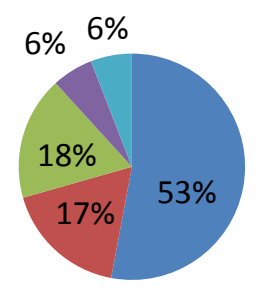

Table 1 shows the number of pediatric patients seen in a week in OP. Most of the respondents see 1-10 pediatric patients in a week. Table 2 shows the clinician's choice for the ideal requirement of a restorative material. A majority of the practitioners $(84 \%)$ feel that the restorative material chosen should be able to prevent further ingress of bacteria into the tooth. 


\section{JMSCR Vol||4||Issue||06||Page 11166-11172||June}

TABLE 1:

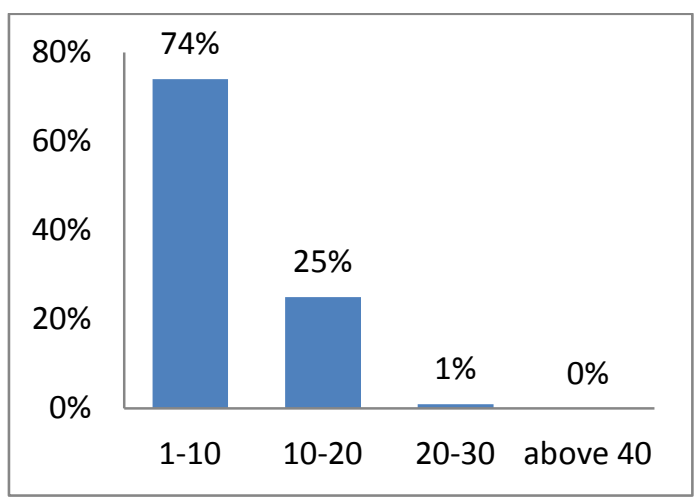

TABLE 2

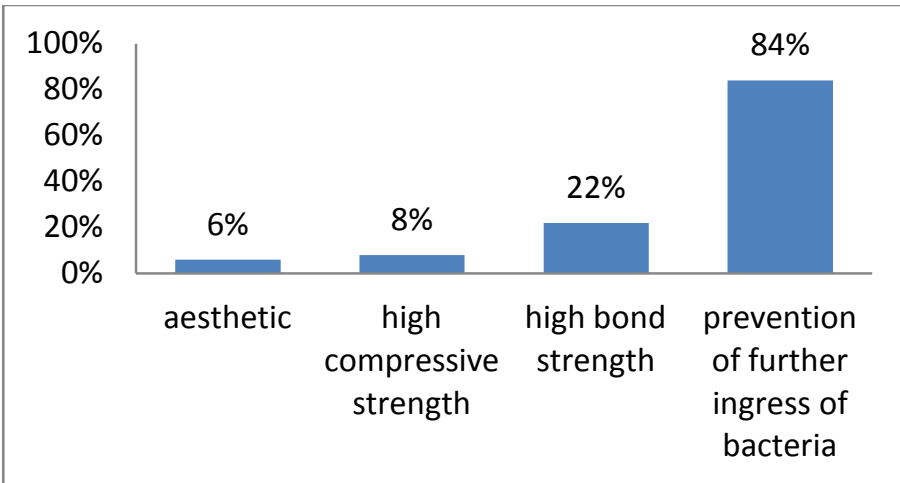

TABLE 3:

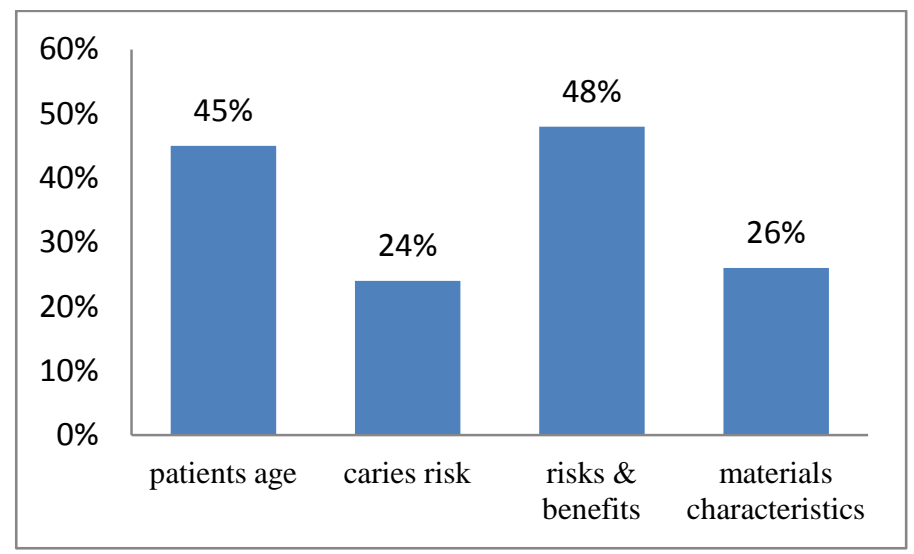

\section{TABLE 4:}

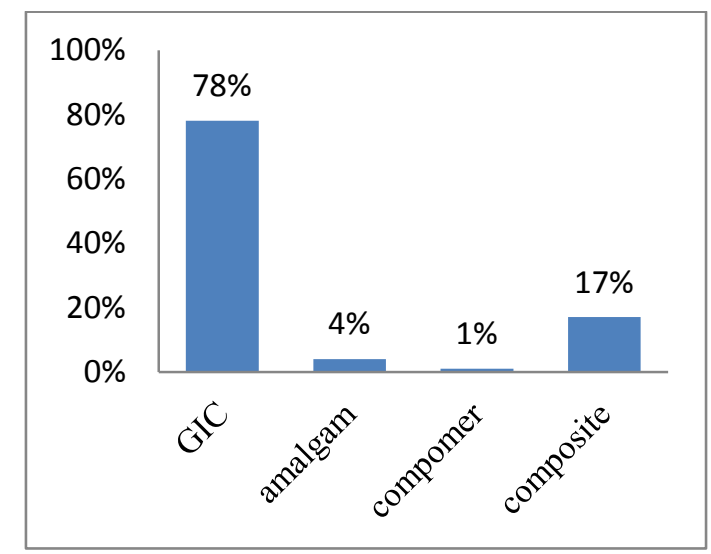

The factors that affect the clinician's choice of restorative material are the risks and benefits of various materials $(48 \%)$ followed by the patients age and ability to co-operate $(45 \%)$, the characteristics of different materials $(26 \%)$ and caries risk $(24 \%)$ (refer Table 3 ).

Table 4 shows that GIC was chosen as the material of choice for primary anterior teeth in children by $78 \%$ of the practitioners followed by composite (17\%), amalgam(4\%) and compomer $(1 \%)$

\section{TABLE 5:}

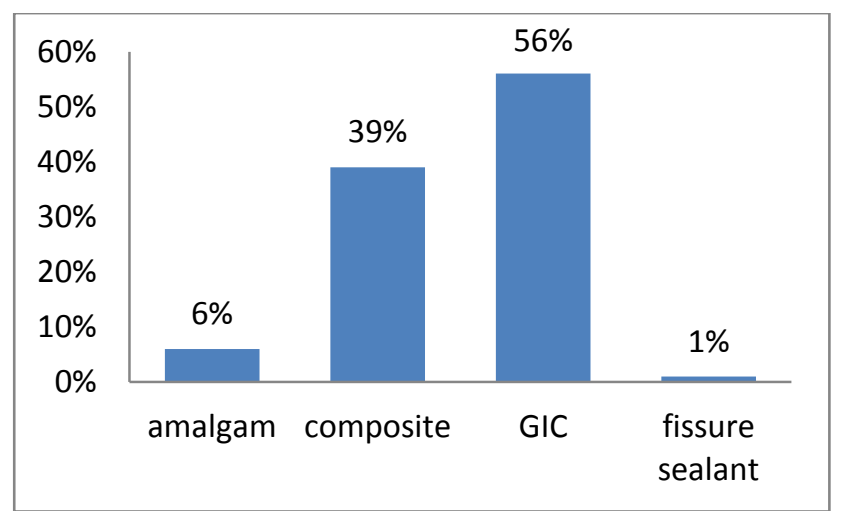

TABLE 6:

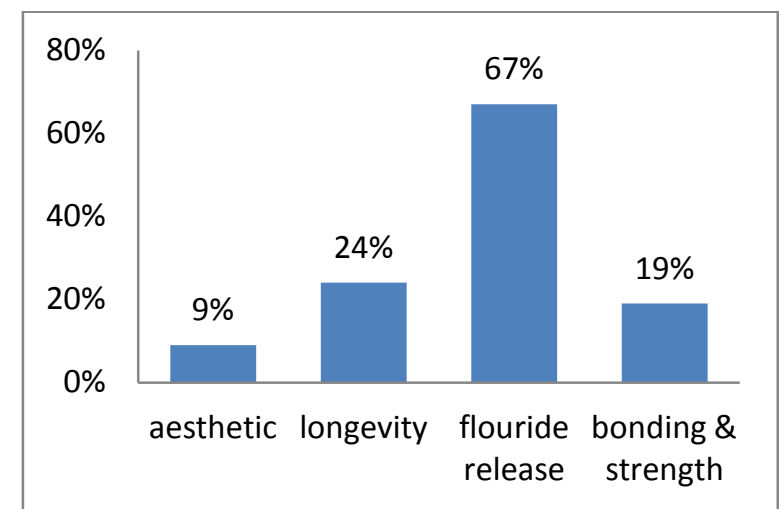

Table 5 reveals that GIC was also chosen by $56 \%$ of the respondents as a material of choice for deciduous posterior teeth in children. The other materials of choice in order of their preference were composite(39\%), amalgam(6\%) and fissure sealant $(1 \%)$. The main reason for their choice of material was due to fluoride release followed by longevity of the material, bonding and strength and then aesthetics(refer Table 6). 


\section{TABLE 7:}

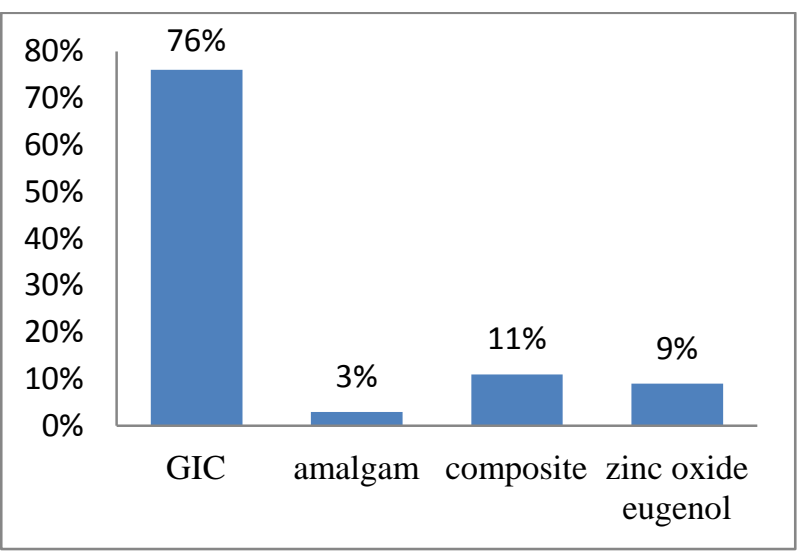

TABLE 8:

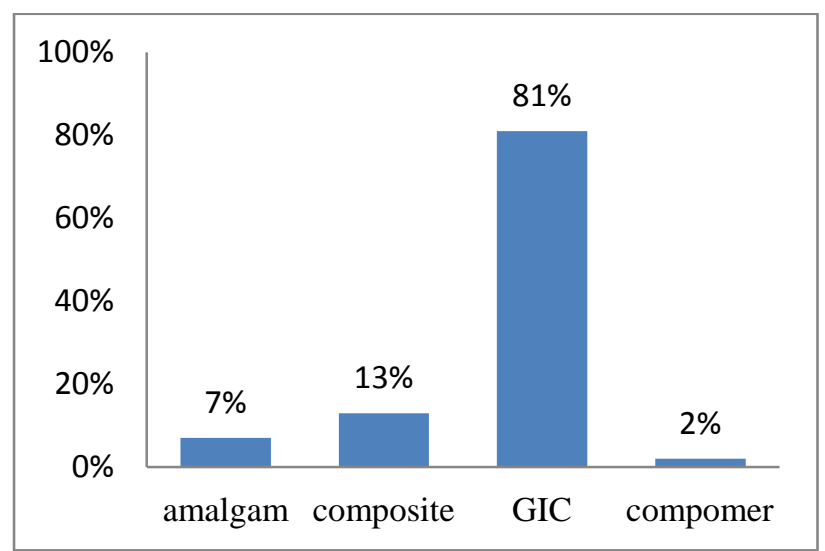

Table 7 shows that GIC was the material of choice for deep caries without pulp exposure in primary teeth of children for $76 \%$ of respondent. Composite was chosen by $11 \%$, Zinc oxide eugenol by $9 \%$ and amalgam by $3 \%$. According to Table 8, 81\% dentists used GIC for restoration of proximal caries in the primary teeth of children. Composite was used by $13 \%, 7 \%$ respondents use silver amalgam and $2 \%$ use compomer.

Table 9 shows that for sterile mechanical exposure of the pulp, Dycal was the material of choice for $44 \%$ respondents. RCT was preferred by $23 \%$ and pulpotomy was the choice of $19 \%$ respondents. Other procedures preferred were extraction by $9 \%$ and zinc oxide eugenol by $5 \%$.

\section{TABLE 9:}

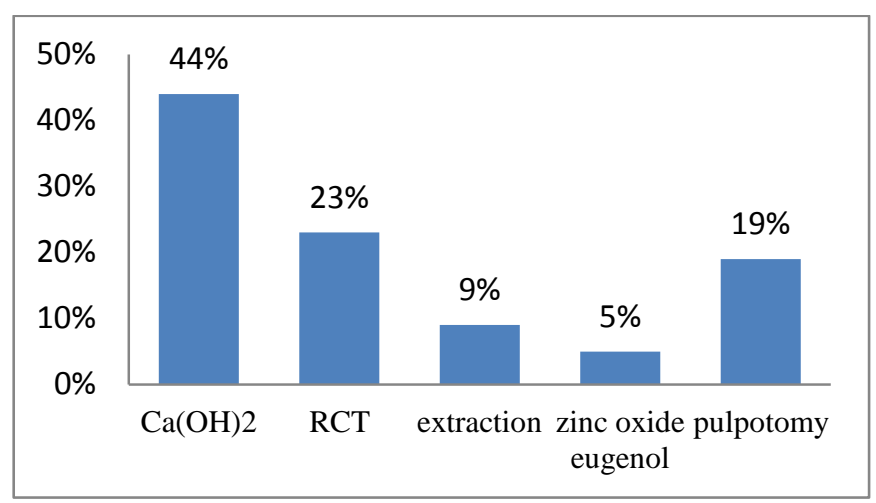

\section{TABLE 10:}

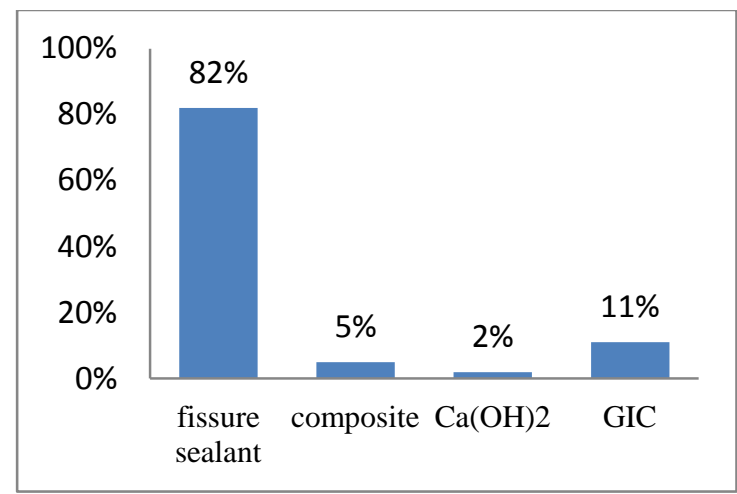

Table 10 shows that the material of choice for non-cavitated incipient carious lesion in primary teeth was Pit and fissure sealant selected by $82 \%$ dentists . GIC was chosen by $11 \%$ respondents. $5 \%$ were using composite. $\mathrm{Ca}(\mathrm{OH}) 2$ was chosen by $2 \%$ dentists.

\section{TABLE 11:}

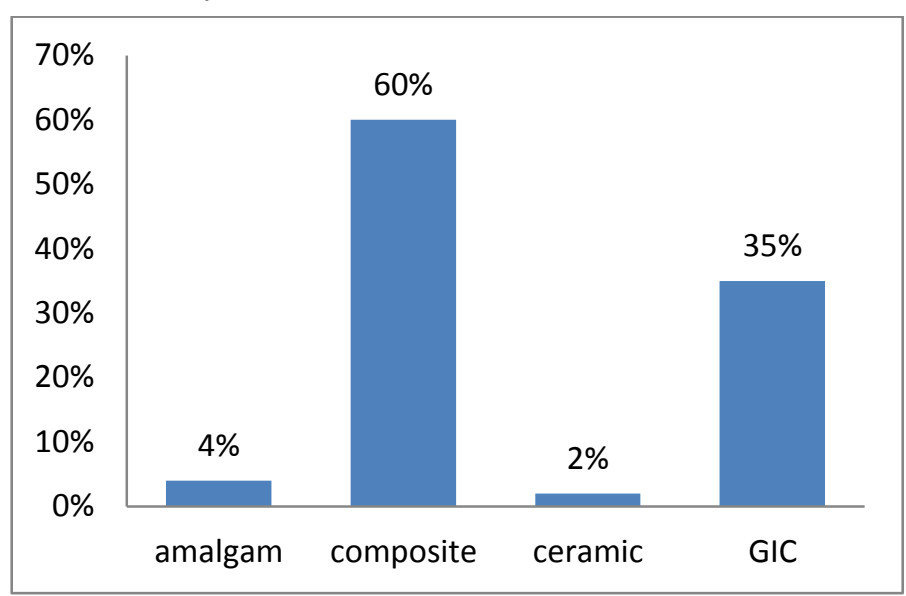

The material of choice for tooth fracture of primary teeth in children was chosen to be composite $(60 \%)$ followed by GIC (35\%), amalgam $(4 \%)$ and ceramic $(2 \%)($ refer Table 11$)$. 
TABLE 12:

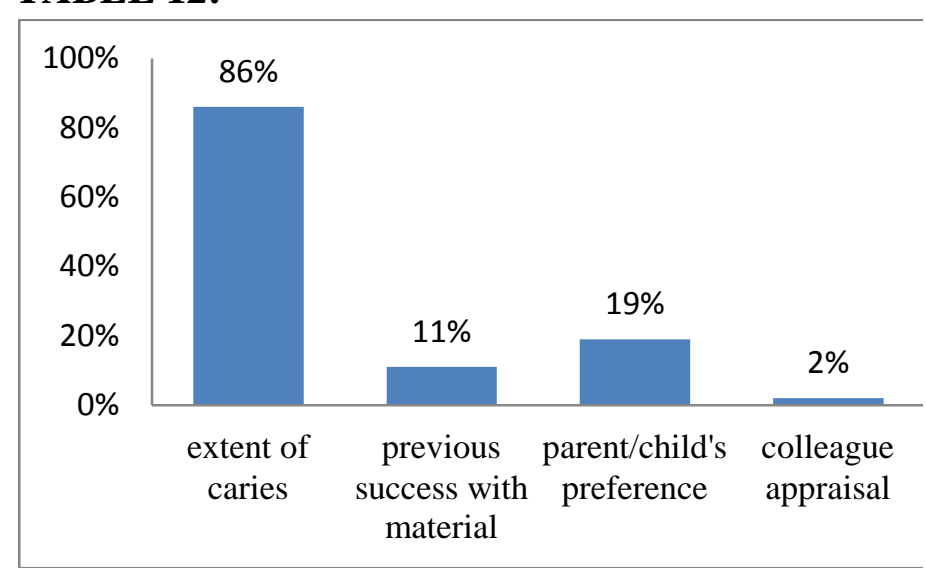

Table 12 depicts the factors that decided the choice of material by a majority of the practitioners was based on the extent of caries $(86 \%)$. The other factors were parent/child's preference $(19 \%)$, previous success with material $(11 \%)$ and colleague appraisal $(2 \%)$.

\section{TABLE 13:}

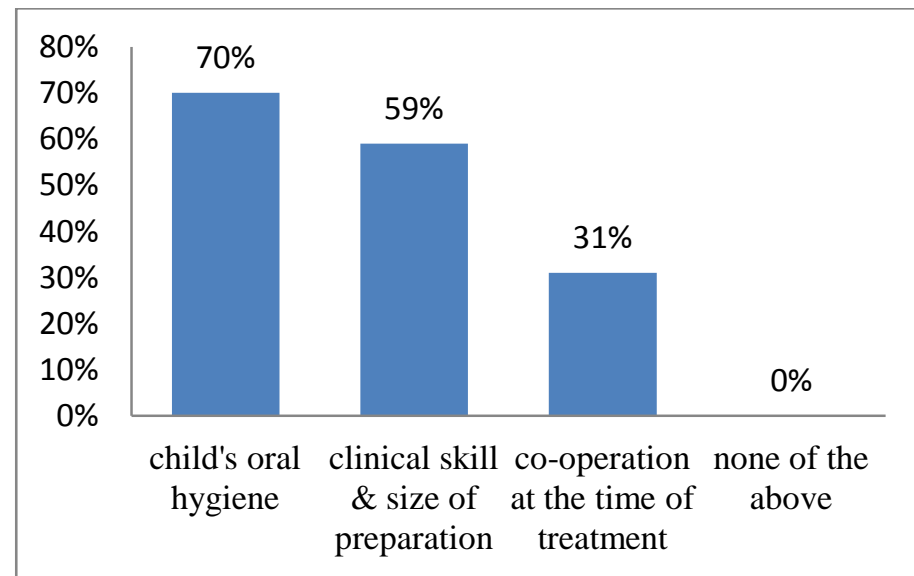

Table 13 shows that according to $70 \%$ of the practitioners the factor that influence the success of a restoration in children is the child's oral hygiene. The other factors chosen included clinical skill and size of preparation and cooperation at the time of treatment.

\section{DISCUSSION}

Despite modern dental materials and techniques, the oral cavity presents a demanding environment for restorative materials. Restorative materials break down for a variety of reasons including: dietary factors, masticatory stresses, the adhesive nature of plaque, the complex and different structures of cementum, dentin, and enamel, and interaction with other materials. The consequences of breakdown include recurrent caries, surface wear, microleakage, marginal fracture, discoloration, corrosion etc, ${ }^{[6]}$. A majority of the clinicians chose that an ideal restorative material is the one that prevents further ingress of bacteria between the restoration and the tooth.

The factors that have to be taken into account while choosing a restorative material is the various risks and benefits $(48 \%)$ of that chosen material(indications, properties, advantages, disadvantages and complications) followed by the patients age and ability to co-operate $(45 \%)$ i.e., whether the child can handle rubber dam/local anesthetic/the time of restoration span. The other factors include caries risk(number of carious teeth, likelihood of further caries attack) ${ }^{[7]}$ and characteristics of different restorative materials.

Restoration of primary teeth differs from restoration of permanent teeth, due in part to the differences in tooth morphology. The mesiodistal diameter of a primary molar crown is greater than the cervicoocclusal dimension. The enamel and dentin are thinner. The cervical enamel rods slope occlusally, ending abruptly at the cervix rather than being oriented gingivally and gradually becoming thinner as in permanent teeth ${ }^{[8]}$. The pulp chambers of primary teeth are proportionately larger and closer to the surface. Primary teeth contact areas are broad and flattened rather than being a small distinct circular contact point, as in permanent teeth. The clinical crown heights of primary teeth is also shorter. Hence an appropriate treatment plan should be formulated in the treatment of an pediatric patient ${ }^{[9]}$.

GIC was the choice of material for primary anterior and posterior dentition in children. Glass ionomers have several properties that make them favorable to use in children:

1. chemical bonding to both enamel and dentin

2. thermal expansion similar to that of tooth structure

3. biocompatibility

4. uptake and release of fluoride 
5. decreased moisture sensitivity when compared to resins ${ }^{[10]}$.

It was chosen because of its fluoride releasing $(67 \%)$ property. Release of fluoride ions from the material could be a substantial benefit because fluoride can enrich neighbouring enamel or dentin to combat caries ${ }^{[11]}$. GIC was also chosen as the material of choice for deep caries without pulp exposure by $76 \%$ of the respondents and for proximal caries by $81 \%$ of the clinicians in deciduous teeth in children. Similar findings was reported in a survey by Rafi.A.Togoo et al ${ }^{[12]}$ in 2011 who reported GIC as the choice of material for posterior, anterior, proximal caries and deep caries without pulp exposure.

When a pinpoint mechanical exposure of the pulp is encountered during cavity preparation or following a traumatic injury, a biocompatible radiopaque base such as MTA or calcium hydroxide may be placed in contact with the exposed pulp tissue ${ }^{[13]}$. Our observations concluded that majority of the respondents are using calcium hydroxide powder(44\%) to do direct pulp capping with mechanical exposure of pulp. The greatest benefit of Calcium hydroxide is the stimulation of reparative dentin bridge. This is due to its high alkalinity, which leads to enzyme phosphatase being activated resulting in the release of inorganic phosphate from the blood (calcium phosphate). It also has an antibacterial action ${ }^{[14]}$. The result reported by Rafi.A.Togoo et al showed similar results.

For non-cavitated incipient carious lesions the material of choice was fissure sealant $(82 \%)$. Pit and fissure caries account for approximately 80$90 \%$ of all caries in permanent posterior teeth and $44 \%$ in primary teeth ${ }^{[15]}$. Sealants reduce the risk of caries in those susceptible pits and fissures. Sealant has been described as a material placed into the pits and fissures of caries-susceptible teeth that micromechanically bonds to the tooth preventing access by cariogenic bacteria to their source of nutrients ${ }^{[16]}$. Same response was observed in the survey carried out by by Rafi.A.Togoo et al in 2011.
The material of choice for tooth fracture of primary teeth in children was chosen to be composite $(60 \%)$. Composites have excellent esthetic properties and are applied most frequently in anterior tooth cavities.

The dentist must make the selection of the material with great care because there are numerous factors to consider when restoring a tooth and the majority of the dentists chose extent of caries as a major factor that influence their choice of material. The success of a restoration is dependent on many factors, the patient, the dentist, and the material. $70 \%$ of the practionners opinion is that a child's oral hygiene is the most important factor followed by clinical skill and size of preparation and co-operation at the time of procedure.

\section{CONCLUSION}

Thus the overall results of this study shows that glass ionomers have been a mainstay of restorative dentistry for children. Their many formulations, clinical uses, and unique advantages have made these materials an essential part of everyday practice for pediatric dentistry. Many new developments have occurred in restorative dentistry for children in recent years. One must develop a clear understanding of the unique features, strengths, weaknesses, and requirements of each material available to be able to apply the right material to the right situation. The present study has provided useful information on the selection of restorative materials in various clinical situations for restoring the primary teeth in pediatric patients.

\section{REFERENCES}

1. Saha Mk, Saha Sg. Restoration Of Anterior Teeth With Direct Composite Veneers In Amelogenesis Imperfecta. International Journal Of Dental Clinics. 2011;3(2):99-100.

2. Gaikwad A. Reinforcing Esthetic With Fiber Post. International Journal Of Dental Clinics.2011;3 (2):89-90. 
3. 3. Ks R, Vanka A, Shashikiran N. Portland Cement: A Building Of Evidence For Clinical Use. International Journal of Dental Clinics. 2011;3(1):52-5.

4. The Continuum of Restorativem Aterialsin Pediatric Dentistry-Are View For The Clinician. Joelh .B Ergd, Dsm. Americana Cademyo F Pediatric Dentistry. Pediatric Dentistry-20:2, 1998.

5. Clinician's Choices Of Restorative Materials For Children In Abha City, Saudi Arabia. Rafi.A.Togoo, Zakirulla Meer, Syed.M.Yasin, Mohammad.S.AlShaya, Nausheen.S.Khan. International Journal Of Dental Clinics Volume 3 Issue 3 July - September 2011.

6. Materials, Methods, And Indications For The Restoration Of Posterior Teeth. Http://Web.Health.Gov/Environment/Ama lgam1/Appendixi-Sectionii.Htm.

7. Pediatric Restorations. Matt Fischer, Albuquerque May $20 \quad 2011$. Http://Www.Nmhr.Org/Retreat/2011/20P1-D.Pdf

8. Waggoner Wf. Restorative Dentistry For The Primary Dentition. In: Pinkham Jr, Casamassimo Ps, Fields Hw Jr, Mctigue Dj,Nowak Aj, Eds. Pediatric Dentistry: Infancy Through Adolescence. 4th Ed. St. Louis, Mo: Elsevier Saunders; 2005:341374.

9. Fuks Ab, Heling I. Pulp Therapy For The Young Permanent Dentition. In: Pinkham Jr, Casamassimo Ps, Fields Hw Jr, Mctigue Dj,Nowak Aj, Eds. Pediatric Dentistry: Infancy Through Adolescence. 4th Ed. St. Louis, Mo: Elsevier Saunders; 2005:577-592.

10. Mitra Sb, Kedrowski Bl. Long-Term Mechanical Properties Of Glass Ionomers. Dent Mater 1994:10(2):78-82.
11. Fluoride Release From Glass Ionomer Cement: Effect Of Temperature, Time Interval And Storage Conditions. Prashanthi Madhyastha, Ravindran Kotiya, Vivekananda Pai, Ama Khader 10.5055 /Jp-Journals-10031-1039.

12. Clinician's Choices Of Restorative Materials For Children In Abha City, Saudi Arabia. Rafi.A.Togoo, Zakirulla Meer, Syed.M.Yasin, Mohammad.S.AlShaya, Nausheen.S.Khan. International Journal Of Dental Clinics Volume 3 Issue 3 July - September 2011.

13. Kopel Hm. The Pulp Capping Procedure In Primary Teeth "Revisited". Asdc J Dent Child 1997;64(5):327-33.

14. Indirect Pulp Capping. Olubukola Olatosi, Department Of Child Dental Health, University Of Lagos, And Morenike Ukpong Of The Department Of Child Dental Health, Obafemi Awolowo University Ile-Ife.

15. Brown Lj, Kaste L, Selwitz R, Furman L. Dental Caries And Sealant Usage In Us Children, 1988-1991: Selected Findings From The Third National Health And Nutrition Examination Survey. J Am Dent Assoc 1996;127(3):335-43.

16. Simonsen Rj. Pit And Fissure Sealants. In: Clinical Applications Of The Acid Etch Technique. Chicago, Ill: Quintes-Sence Publishing Co, Inc; 1978:19-42. 